\title{
Influências da variação sazonal e tipos de secagem nas características da droga vegetal - raízes de Pfaffia glomerata (Spreng.) Pedersen (Amaranthaceae)
}

\author{
Vigo, C.L.S.; Narita, E.; Marques, L.C.* \\ Laboratório de Farmacognosia, Departamento de Farmácia e Farmacologia, \\ Universidade Estadual de Maringá, Maringá, PR.
}

Recebido para publicação em: 04/02/2004 Aceito para publicação em: 10/09/2004

\begin{abstract}
RESUMO: Analisou-se a variação sazonal e a influência de diferentes tipos de secagem (sol, sombra e estufa) no teor de saponinas e nas características físico-químicas da droga vegetal - raízes de Pfaffia glomerata (Spreng.) Pedersen (Amaranthaceae). A avaliação sazonal apontou a ocorrência de diferenças significativas nos teores de extrativos (maior no inverno: $61,1 \% \pm 1,9$ ), saponinas totais (maior no inverno: $17,1 \pm 0,2 \%$ ), e entre cinzas totais (maiores no inverno e primavera: $6,5 \pm 0,4$ e $6,5 \pm 1,0 \%$, respectivamente) e cinzas insolúveis em ácido(maiores no verão e outono: $0,57 \pm 0,11$ e $0,44 \pm 0,18 \%$, repectivamente). Quanto à variação sazonal do teor de saponinas, o valor do lote colhido no inverno foi maior do que nas outras estações, confirmando o conceito geral de maior ocorrência de ativos em órgãos subterrâneos no inverno. Quanto à influência dos métodos de secagem, o lote seco ao sol forneceu maior teor de extrativos $(61,2 \pm 2,3 \%)$ do que os lotes secos na sombra e em estufa, contradizendo a regra geral de que a radiação solar degrada os ativos vegetais. Esse mesmo perfil de dados ocorreu com relação ao teor de saponinas, pois o lote seco ao sol mostrou maior valor $(15,4 \%)$ do que daqueles secos na sombra ou em estufa (14,4 e 11,6\%, respectivamente). Desta forma, verificou-se que, de fato, ocorre variação sazonal nas raízes de $P$. glomerata, particularmente, no que diz respeito aos teoes de extrativos, cinzas e saponinas totais, sendo que essas variações indicam maior concentração de ativos nos períodos de inverno e primavera. Dentre os métodos de secagem testados, o emprego do sol parece favorecer os teores de saponinas e de extrativos, embora tal conclusão mereça ser melhor investigada.
\end{abstract}

Unitermos: Pfaffia glomerata; avaliação da qualidade; variação sazonal; tipos de secagem.

ABSTRACT: Influence of seasonal variation and drying on root's characteristics derived from Pfaffia glomerata (Spreng.) Pedersen (Amaranthaceae). The seasonal variation and the influence of drying (sun, shadow and hot-house greenhouse) were analysed in relation to the total saponin content and physicochemical characteristics. The seasonal evaluation detected significant differences in the parameters of extractable matter (larger 
in winter: $61.1 \% \pm 1.9$ ), total saponin content (larger in winter; $17.1 \pm 0.2 \%$ ) and between total ash (larger in winter and spring; $6.5 \pm 0.4$ and $6.5 \pm 1.0 \%$, respectively) and acid-insoluble ash (larger in summer and autumn; $0.57 \pm 0.11$ and $0.44 \pm 0.18 \%$, respectively). In relation to the seasonal variation of total saponin content, the value of the sample collected in winter was larger than in other seasons, confirming the general rule that the largest content of substances in underground organs occurred in winter. In relation to the influence of drying methods, the sample dried at the sun presented a larger value of extractable matter $(61.2 \pm 2.3 \%)$ than those dried on shadow and in hot-house greenhouse, contradicting the general rule that the sun radiation would degrade natural substances. The same profile was found in relation to the total saponin content, because the sample dried at the sun showed a larger value (15.4\%) than those dried on shadow or in hot-house (14.4 and $11.6 \%$, respectively). However, these conclusions have to be more investigated.

Keywords: Pfaffia glomerata; quality Control; seasonal variation; drying methods.

\section{INTRODUÇÃO}

Nas últimas décadas, o uso de plantas medicinais tem crescido de forma significativa, pois cerca de $90 \%$ da população mundial faz uso de algum tipo de planta na busca de alívio de alguma sintomatologia dolorosa ou desagradável e, desse total, pelos menos $30 \%$ ocorreram por indicação médica (ROBBERS et. al., 1996).

No Brasil, uma das espécies bastante empregadas em medicamentos tônicos é denominada de "ginseng brasileiro", correspondendo às raízes de Pfaffia glomerata (Spreng.) Pedersen, da família Amaranthaceae. Quimicamente, essa espécie é rica em saponinas triterpênicas, das quais destaca-se a $\beta$-ecdisona, citada como o principal ingrediente ativo (SHIOBARA et al., 1992).

A falta de especificações dessa droga vegetal levou a definição de seus parâmetros farmacognósticos básicos (identificação botânica, caracterização macro e microscópica das raízes, cinzas totais e insolúveis, teor de extrativos e índice de espuma), e também da espécie afim Hebanthe paniculata (VIGO et al., 2004), promovendo-se dessa forma a distinção entre ambas. Em termos de quantificação analítica, desenvolveu-se também a validação da metodologia espectrofotométrica de saponinas totais, segundo normativa federal para essa área (VIGO et al., 2003).

No entanto, para se garantir a padronização completa de um produto fitoterápico, necessitase conhecer a influência de outros fatores sobre a qualidade química da matéria-prima vegetal, pois de fato as raízes podem apresentar variabilidade ao longo das diversas estações do ano ou ao serem secas e extraídas de diferentes formas. Conhecer tais relações representa passo importante no domínio global da tecnologia referente a essa droga vegetal.

Um fator a ser considerado durante a colheita é o estágio de desenvolvimento da planta, pois variações grandes no conteúdo do princípio ativo são freqüentemente observadas quando se varia a época da colheita (OLIVEIRA et al., 1998). Martins e colaboradores (1995) mencionam também que, de acordo com as substâncias presentes na planta, existem horários em que a sua concentração é maior.

Outro fator a ser investigado é a secagem, que tem como objetivo eliminar certa quantidade de água do órgão vegetal, dessa forma possibilitando a conservação das drogas vegetais. Existem processos naturais (secagem ao sol, à sombra, mistos) e artificiais (circulação 
de ar, aquecimento com circulação de ar, vácuo e esfriamento) (OLIVEIRA et al., 1998). A verificação da interferência desses vários tipos de secagem sobre os teores de ativos e as características físico-químicas da droga contribui à utilização do melhor perfil de técnicas que propicie a maior qualidade possível dessa matéria-prima.

\section{MATERIAL E MÉTODOS}

\section{Droga vegetal}

O material vegetal em estudo foi proveniente de cultivo de um pequeno produtor de plantas medicinais da região de Maringá (PR). Os exemplares utilizados já tinham sido anteriormente identificados, com exsicatas devidamente depositadas no herbário da Universidade Estadual de Maringá-HUM e Herbarium Friburguense-FCAB (VIGO et al., 2004).

\section{Variação sazonal}

Coletaram-se raízes em julho (inverno) e outubro (primavera) de 2002, e em janeiro (verão) e abril (outono) de 2003. As raízes dos quatro lotes foram lavadas e escovadas em água corrente da mesma forma devido à grande quantidade de terra presente nas mesmas. Em seguida, foram cortadas manualmente e submetidas à secagem em estufa de ar circulante a $40^{\circ} \mathrm{C}$ por três dias, com as raízes se mostrando quebradiças à pressão manual ao final desse período. Cada lote foi moído em moinho de facas, pesado, e armazenado em potes de plásticos devidamente fechados. As amostras de cada coleta foram avaliadas segundo os itens apresentados em Controle de qualidade da droga, descritos abaixo.

\section{Tipos de secagem}

A amostra das raízes da coleta de abril de 2003 (outono) foi submetida a três diferentes tipos de secagem, a saber:

- secagem à sombra por cinco dias;

- secagem ao sol por três dias;

- secagem em estufa a $40^{\circ} \mathrm{C}$ por três dias;

\section{Controle de qualidade da droga}

Algumas metodologias forma empregadas com o objetivo de se obter dados que apontassem possíveis alterações quanto à variação sazonal e aos processos de preparo da droga vegetal:

\section{a) Teor de extrativos (WHO, 1998)}

Ferveu-se sob refluxo, por $15 \mathrm{~min}, 2 \mathrm{~g}$ da amostra em $100 \mathrm{ml}$ de água destilada. Esfriouse e filtrou-se para um balão volumétrico de $100 \mathrm{ml}$ e completou-se o volume com água destilada. Com uma pipeta volumétrica, transferiu-se $20 \mathrm{ml}$ para um pesa-filtro previamente tarado. Evaporouse todo o solvente em banho-maria, colocou-se em estufa à temperatura de $105^{\circ} \mathrm{C}$ por 2 horas, resfriou-se em dessecador e pesou-se. O teor de extrativos foi calculado em massa percentual, pela média de cinco determinações. 


\section{b) Cinzas totais (FARMACOPÉIA BRASILEIRA, 1998)}

Carbonizou-se cerca de $3 \mathrm{~g}$ da amostra exatamente pesadas, acondicionadas em um cadinho de porcelana estabilizado e previamente pesado. Colocou-se na mufla a $400^{\circ} \mathrm{C}$ e deixou-se por 45 horas até peso constante; após retirar, esfriou-se no dessecador e pesou-se até peso constante. Calculou-se o teor de cinzas totais pela diferença entre o peso do conjunto cadinho e a amostra antes e após a incineração. Cinco medidas de cinzas totais foram realizadas para cada amostra.

\section{c) Cinzas insolúveis em ácido (FARMACOPÉIA BRASILEIRA, 1998)}

Adicionaram-se $25 \mathrm{ml}$ de ácido clorídrico a 10\% no cadinho com os resíduos das cinzas totais, ferveu-se na manta por $5 \mathrm{~min}$, filtrou-se duas vezes em papel de filtro com tarja preta. Lavou-se o papel de filtro com água fervente até o $\mathrm{pH}$ tornar-se neutro. Acondicionou-se 0 papel de filtro em uma segundo cadinho tarado e pesado. Carbonizou-se a $100^{\circ} \mathrm{C}$ e colocouse na mufla por 4-5 horas até peso constante; retirou-se, esfriou-se no dessecador e pesou-se o cadinho.

\section{d) Índice de espuma (WHO, 1998)}

Ferveu-se sob refluxo, durante $30 \mathrm{~min}, 1 \mathrm{~g}$ da droga vegetal com $100 \mathrm{ml}$ de água destilada. Depois de esfriada e filtrada para um balão volumétrico, a amostra teve seu volume completado para $100 \mathrm{ml}$. Preparou-se uma série de diluições em tubos de ensaio, diluindo-se progressivamente o extrato aquoso, Cada tubo foi marcado ao nível de $10 \mathrm{ml}$ da solução e $1 \mathrm{~cm}$ acima. Após serem agitadas no sentido do seu comprimento durante 15 segundos, as amostras foram deixadas em repouso por $15 \mathrm{~min}$, verificando-se em qual tubo se formou um anel de espuma persistente de aproximadamente $1 \mathrm{~cm}$ de altura. Calculou-se o índice de espuma com base na diluição do tubo onde se formou o anel de espuma persistente $(a=$ volume em $\mathrm{mL}$ da decocção usada para preparar a diluição no tubo onde a espuma de $1 \mathrm{~cm}$ foi observada).

\section{e) Determinação da perda por dessecação (FARMACOPÉIA BRASILEIRA, 1998)}

Pesou-se cerca de $2 \mathrm{~g}$ de droga vegetal em pesa-filtro previamente tarado. Colocou-se em estufa a $105^{\circ} \mathrm{C}$ por 2 horas, deixou-se esfriar em dessecador durante 30 min., repetindo-se o processo até peso constante. Os resultados foram expressos através da média de cinco determinações.

F) Determinação das saponinas totais por espectrofotometria (VIGO et al., 2003)

Pesou-se 0,2 $\mathrm{g}$ da droga (raízes pulverizadas) em um erlenmeyer e desengordurou-se com $30 \mathrm{ml}$ hexano por 2 horas. Filtrou-se e secou o pó em estufa. Extraiu-se sob refluxo $3 \times 20 \mathrm{ml}$ metanol-água (4:1) por $30 \mathrm{~min}$. Filtrou-se e concentrou-se o metanol em evaporador rotatório. Extraiu-se com n-butanol saturado com água (1:1) 3x $20 \mathrm{ml}$ em ampola de separação. Recolheuse fração butanólica e concentrou-se no evaporador rotatório. Juntou-se à fase butanólica e evaporou-se a solução em banho-maria a $40^{\circ} \mathrm{C}$ por 4 horas. Colocou-se na estufa por $1 \mathrm{~h}$ para secar, pesou-se e dissolveu-se o resíduo em 100ml de água (solução final). Desta solução final, retirou-se uma alíquota de $1 \mathrm{ml}$ para a reação de complexação, adicionando-se $1 \mathrm{ml}$ de cloreto de cobalto a $0,2 \%$ e $1 \mathrm{ml}$ de ácido sulfúrico concentrado. Realizou-se a leitura espectrofotométrica em triplicata da solução a $284 \mathrm{~nm}$.

\section{Análise estatística}

Os dados obtidos com relação às variações sazonais foram avaliados por análise de variância (ANOVA), seguida pelo teste de Duncan a posteriori, $\mathrm{p}<0,05$. 


\section{RESULTADOS E DISCUSSÃO}

\section{Variações sazonais}

Foram realizados os testes de teor de extrativos (aquoso a quente), cinzas totais, cinzas insolúveis em ácido, índice de espuma, perda por dessecação e doseamento de saponinas totais para os quatro lotes em avaliação (inverno, primavera, verão e outono), os quais expressam a variação sazonal dos constituintes das raízes ao longo de 1 ano de avaliação (Tabela 1).

Tabela 1. Variações sazonais das raízes de Pfaffia glomerata com relação a parâmetros físicoquímicos.

\begin{tabular}{l|l|l|l|l|l|}
\hline \multicolumn{1}{|c|}{ Teste } & $\mathbf{n}$ & Inverno & Primavera & Verão & Outono \\
\hline Cinzas totais (\%) & 5 & $6,5 \pm 0,4^{\#}$ & $6,5 \pm 1,0^{\#}$ & $4,3 \pm 0,1$ & $4,4 \pm 0,2$ \\
Cinzas insolúveis (\%) & 4 & $0,19 \pm 0,06$ & $0,19 \pm 0,16$ & $0,57 \pm 0,11^{*}$ & $0,44 \pm 0,18^{*}$ \\
\hline Índice de espuma (mL) & 5 & $433 \pm 91$ & $433 \pm 91$ & $400 \pm 92$ & $467 \pm 75$ \\
\hline Perda por dessecação (\%) & 5 & $7,9 \pm 0,7$ & $6,2 \pm 0,2$ & $5,9 \pm 0,1$ & $3,3 \pm 0,1$ \\
\hline Saponinas totais (\%) & 3 & $17,1 \pm 0,2$ & $14,6 \pm 0,3$ & $11,9 \pm 0,1$ & $11,6 \pm 0,2$ \\
\hline Teor de extrativos (\%) & 5 & $61,1 \pm 1,9^{*}$ & $55,9 \pm 2,9$ & $57,0 \pm 3,0$ & $59,2 \pm 1,7$ \\
\hline
\end{tabular}

* Estatisticamente diferente do verão e outono; * Estatisticamente diferente do inverno e primavera;

* Estatisticamente diferente da primavera e verão.

O conteúdo de substâncias extraíveis ou teor de extrativos determina a quantidade de substâncias com possibilidade de serem extraídas por um determinado solvente, no caso água a quente. Esses dados, apesar de não indicarem que no resíduo se encontram os constituintes ativos, estabelecem algumas condições adicionais para o controle de qualidade da matériaprima vegetal, úteis por sua praticidade e baixo custo (MELLO; PETROVICK, 2000). Considerandose o teor de extrativos obtido para as raízes de $P$. glomerata, pôde-se verificar que no inverno há uma maior concentração das substâncias extraíveis em água a quente, que decresce com a primavera até atingir o menor valor, no verão voltando a crescer e assim se mantendo no outono. O teor de saponinas totais segue variação sazonal similar, com maior concentração no inverno e decréscimo nas outras estações atingindo valor mínimo no outono, embora sem significância estatística pelo baixo número de replicatas. Esses dois perfis coincidem com os conceitos gerais de fisiologia vegetal, que apontam maior ocorrência de ativos em órgãos subterrâneos no inverno (OLIVEIRA et al., 1998).

A avaliação sazonal apontou também diferenças estatísticas nos parâmetros das cinzas totais e insolúveis em ácido, com os lotes do inverno e primavera apresentando valores acima dos lotes das duas outras estações para cinzas totais, e o contrário para cinzas insolúveis (menores valores no inverno e primavera). Os maiores valores de cinzas totais no inverno e primavera (considerando-se menores valores de cinzas insolúveis, aumentam os valores de cinzas 
fisiológicas na droga, relacionadas aos minerais presentes no conteúdo celular) coincidem também com o ciclo vegetal, quando ocorre maior acúmulo de substâncias nos órgãos subterrâneos no período do inverno e início de sua mobilização na primavera. Quantos às cinzas insolúveis (valores relacionados a sujidades externas) embora todas as raízes tenham sido limpas pelas mesmas pessoas tentando-se adotar o mesmo critério rígido de lavagem, as diferenças encontradas mostram que tal uniformidade não foi real e é provável que não exista relação com a variação sazonal em questão.

Na Figura 1 estão expressos os valores de variação sazonal do teor de saponinas, de extrativos e de cinzas totais, os quais mostraram correlação.

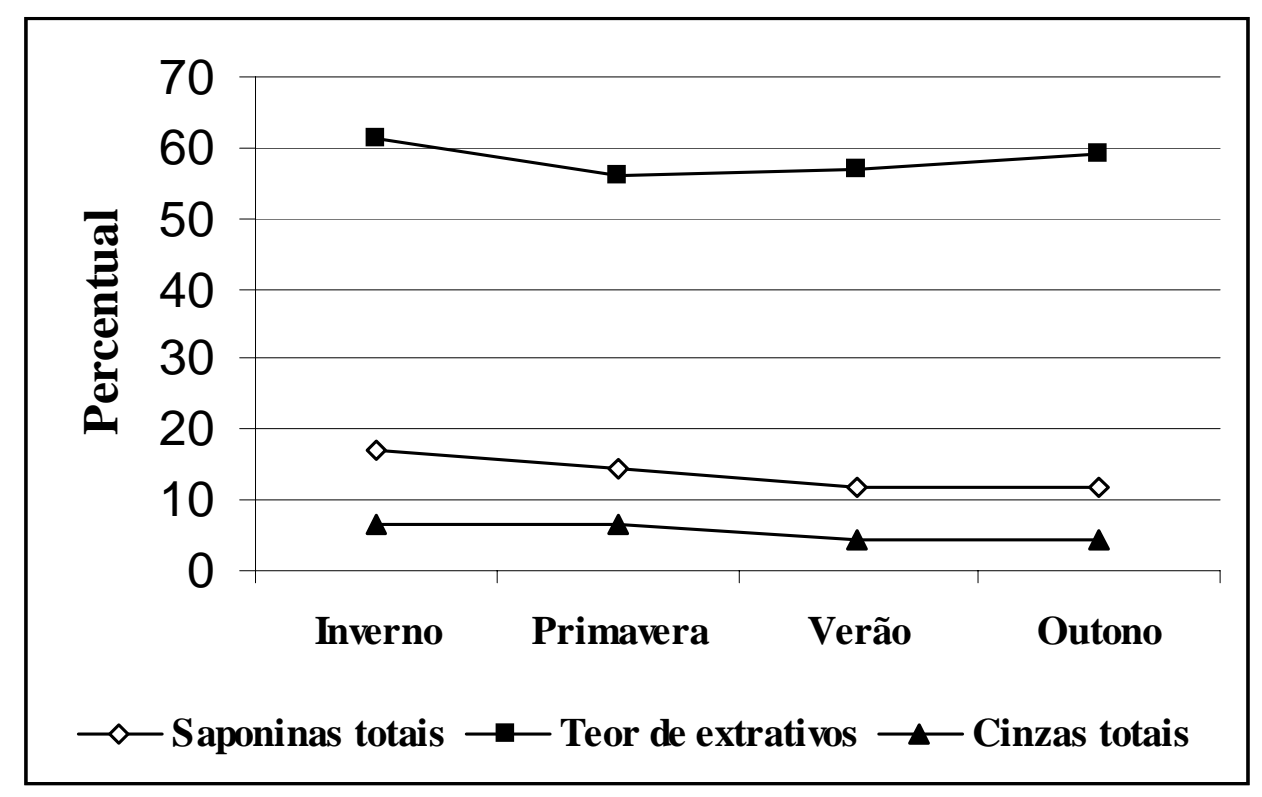

Figura 1. Perfil de variação sazonal das saponinas totais, cinzas totais e teor de extrativos

Em relação aos outros aspectos analisados, os valores obtidos para o índice de espuma mostram uniformidade de dados, os quais, embora com média (433 \pm 84$)$ um pouco acima da estabelecida anteriormente (333 \pm 0 ; VIGO et al., 2004). No entanto, esse teste procura definir valores mínimos para tal parâmetro, com a média atual atingindo valores próximos ao anteriormente encontrado caso se considere a variação expressa no desvio-padrão (349-517).

Quanto à perda por dessecação, os valores obtidos encontram-se abaixo do valor recomendado (15\%) para se evitar a degradação de ativos e proliferação microbiana (OLIVEIRA et al., 1998). Em relação à variação entre os dados, tendo em vista terem sido obtidos a partir da mesma técnica e nas mesmas condições, provavelmente esteja relacionada a diferenças em termos de umidade relativa do ar na época de cada teste, pois tal condição modifica esse parâmetro podendo incorporar de $10-30 \%$ de umidade às drogas vegetais armazenadas (OLIVEIRA et al., 1998).

\section{Métodos de secagem}

O lote de raízes coletado no mês de abril de 2003 foi submetido à secagem ao sol por três dias, à sombra por cinco dias e em estufa de ar circulante $40^{\circ} \mathrm{C}$ também por três dias; não foram realizadas avaliações quantitativas da umidade após esses processos. Cada um desses sub- 
lotes foi avaliado pelo conjunto de técnicas de controle de qualidade aplicado na variação sazonal. Os resultados obtidos constam da Tabela 2.

Tabela 2. Valores dos testes físico-químicos das raízes (lote de abril/03) submetidas a diferentes métodos de secagem.

\begin{tabular}{|l|c|c|c|c|}
\hline \multicolumn{1}{|c|}{ Teste } & $\mathbf{n}$ & À sombra & Ao sol & Em estufa \\
\hline Índice de espuma (mL) & 3 & $333 \pm 0$ & $333 \pm 0$ & $433 \pm 91$ \\
\hline Saponinas totais (\%) & 2 & 14,4 & 15,4 & 11,6 \\
\hline Teor de extrativos (\%) & 3 & $55,7 \pm 1,0$ & $61,2 \pm 2,3$ & $59,2 \pm 1,7$ \\
\hline
\end{tabular}

Dos três métodos utilizados, a secagem ao sol foi a que produziu maiores valores particularmente no teor de extrativos e de saponinas totais. Esses resultados são inesperados, pois contradizem regras gerais de que a radiação solar degradaria os ativos e diminuiria os valores de controle de qualidade correspondentes (OLIVEIRA et al., 1998). Essa diminuição pela ação do sol é marcante em relação às substâncias voláteis, como óleos essenciais e alguns alcalóides, mas não para saponinas que são mais termo-resistentes e aceitariam, em tese, métodos empregando temperatura acima de $40^{\circ} \mathrm{C}$. Por outro lado, se o aumento de temperatura favorecesse de fato a geração de ativos nas raízes de $P$. glomerata, o método em estufa deveria ter produzido valores abaixo do método com sol, mas acima da técnica à sombra, o que não ocorreu e parece, portanto, não representar uma relação expressiva com aumento de temperatura, como já foi verificado em outras drogas vegetais, como o guaco (LOPES et al., 1998). No entanto, pelo pequeno número de repetições realizado neste trabalho, essa definição precisa ser reavaliada para esta droga vegetal.

Em relação aos valores de índice de espuma, os dados obtidos foram estáveis nos lotes secos ao sol e à sombra, aumentando no lote seco em estufa, embora a faixa de variação esteja próxima dos limites mínimos anteriormente estabelecidos, não parecendo representar também uma influência do método de secagem nesse parâmetro.

\section{CONCLUSÕES}

Verificou-se que ocorre de fato variação sazonal nas raízes de $P$. glomerata, particularmente, nos teores de extrativos, cinzas e saponinas totais. O perfil dessas variações coincide com maior concentração de ativos no período do inverno e primavera.

Em relação aos teores de cinzas, os resultados obtidos complementam dados anteriormente definidos (cinzas totais $=4,2 \pm 0,5 \%$ e cinzas insolúveis $=0,11 \pm 0,09 \%$; VIGO et al., 2004) demonstrando que os limites máximos podem ultrapassar a faixa de $6,5 \pm 1,0$ para cinzas totais e de $0,5 \pm 0,2 \%$ para cinzas insolúveis. Os outros fatores não apresentam alterações dignas de nota.

Dos métodos de secagem, o emprego do sol parece favorecer o teor de saponinas e de extrativos, embora tal conclusão mereça ser melhor investigada. 


\section{AGRADECIMENTOS}

Os autores agradecem ao CNPq/PIBIC/UEM pelo apoio financeiro.

\section{REFERÊNCIAS}

FARMACOPÉIA BRASILEIRA. 4.ed. São Paulo: Atheneu, 1998.

LOPES, M.L.A.P.; ROCHA, L.M.; SANTOS, E.V.M.; SAHARAPIN, N.; ALMEIDA, J.M.L. Influência do processo de secagem na fabricação de tintura de guaco - Mikania glomerata Spreng. (Asteraceae). In: Simpósio de plantas medicinais do Brasil, 15 Programa e resumos. Águas de Lindóia: Unifesp, 1998.

MARTINS, E.R.; DE CASTRO, D.M.; CASTELLANI, D.C.; DIAS, J.E. Plantas medicinais. Viçosa: Universidade Federal de Viçosa, 1995.

MELLO, J.C.P.; PETROVICK, P.R. Quality control of Baccharis trimera (Less) DC (Asteraceae) hydroalchoolic extracts. Acta Farmaceutica Bonaerense, v.19, n.3, p.211-215, 2000.

OLIVEIRA, F.; AKISUE, G.; AKISUE, M.K. Farmacognosia. São Paulo: Atheneu, 1998.

ROBBERS, J.E.; SPEEDIE, M.K.; TYLER, V.E. Pharmacognosy and pharmacobiotechnology. Baltimore: Williams \& Wilkins, 1996.

SHIOBARA, Y.; INOUE, S.; KATO, K.; YUKARI, N.; NISHIGUCHI, Y.O.; NISHIMOTO, N.; OLIVEIRA, F.; AKISUE, G.; AKISUE, M.K.; HASHIMOTO, G. A nortripernoid, triterpenoids and ecdysteroids from Pfaffia glomerata. Phytochemistry, v.32, n.6, p.1527-30, 1993.

VIGO, C.L.S.; NARITA, E.; MARQUES, L.C. Validação da metodologia de quantificação espectrofotométrica das saponinas de Pfaffia glomerata (Spreng.) Pedersen - Amaranthaceae. Revista Brasileira de Farmacognosia, v.13, supl. 2, p.46-49, 2003.

VIGO, C.L.S.; NARITA, E.; MILANEZE-GUTIERREZ, M.A.; RIBEIRO, P.G.F.; MARQUES, L.C. Caracterização farmacognóstica comparativa de Pfaffia glomerata (Spreng.) Pedersen e Hebanthe paniculata Martius - Amaranthaceae Kuntze. Revista Brasileira de Plantas Medicinais, Botucatu, v.6, n.2, p.7-19, 2004.

WORLD HEALTH ORGANIZATION. Quality control methods for medicinal plant materials. Geneva: WHO, 1998.

Rev. Bras. Farmacogn., V. 14, n. 2, jul.-dez. 2004.

*Autor para correspondência
Prof. Dr. Luís Carlos Marques
Universidade Estadual de Maringá
Departamento de Farmácia e Farmacologia
Av. Colombo 5790, Bloco T22
87020-900 - Maringá - PR
Email: Imarques@apsen.com.br

